Article

\title{
Research on the Risk Assessment of Qingdao Marine Disaster Based on Flooding
}

\author{
Qi Liao ${ }^{1}$, Ge Yu ${ }^{1, *}$, Wensheng Jiang ${ }^{1}{ }^{(}$, Chunxia Lu ${ }^{2, *}$, Yan Ma ${ }^{3}$, Kexiu Liu ${ }^{4}$, Qun Lin ${ }^{5}$ and \\ Yanping Wang ${ }^{1}$
}

1 College of Environmental Science and Engineering, Key Laboratory of Marine Ecology and Environmental Sciences, Ministry of Education, Ocean University of China, Qingdao 266100, China; znliaoqi@163.com (Q.L.); wsjang@ouc.edu.cn (W.J.); wangyanping@stu.ouc.edu.cn (Y.W.) Institute of Geographic Sciences and Natural Resources Research, CAS, Beijing 100101, China Qingdao Meteorological Administration, Qingdao 266003, China; qdyanma@163.com National Marine Information Center, Tianjin 300480, China; kxliu@163.com

Qingdao Economic and Information Technology Committee, Qingdao 266071, China; 18660278976@163.com

* Correspondence: yuge@ouc.edu.cn (G.Y.); lucx@igsnrr.ac.cn (C.L.); Tel.: +86-532-6678-2322 (G.Y.); $+86-010-6488-9780$ (C.L.)

Received: 12 November 2018; Accepted: 13 January 2019; Published: 17 January 2019

\begin{abstract}
The risk of marine disasters based on flooding is one of the most significant natural disasters in coastal zones. It can be said that flooding in coastal zones has typical sea-land characteristics. Yet, relatively little research has been done in this area. Thus, by using the characteristics of marine disaster risk based on flooding in Qingdao and combining marine science and land science methods, this paper constructs a targeted indicator system for the flooding risk from marine disasters from the perspectives of the disaster natural chain and flooding process. According to the results, the Integrated Risk Index of marine disasters based on flooding in Qingdao is 0.3694 , which represents a medium risk level for natural disasters in China's major coastal areas. The first- and third-level indicators with large contribution rates are almost all natural indicators. This indicates that the natural disaster process and disaster chain greatly affect the flooding disaster risk in Qingdao. However, although natural factors play large roles in the risk of disaster, preventive methods implemented by humans can still have a positive effect on disaster reduction. Therefore, human society should still proceed with understanding disasters from natural processes, change their passive response to active adaptation, and actively strengthen preventive measures to alleviate the adverse impacts of increasingly serious natural disasters.
\end{abstract}

Keywords: flooding; marine disaster; risk; coastal city

\section{Introduction}

\subsection{Background}

The impacts of climate change will inevitably influence the whole world [1]. In addition to changes in basic climate elements, climate change will also increase the frequency, intensity, and risk of extreme weather events and natural disasters [2]. Flooding caused by typhoons and storm surges is one of the most significant natural disasters for coastal zones [3,4]. In addition, under the influence of climate change, the growth rate of the regional extreme water level has already reached $2.0-14.1 \mathrm{~mm} / \mathrm{a}$ in China's coastal areas due to extreme weather events and rising sea levels $[5,6]$. Therefore, it is necessary to focus on the flooding caused by marine disasters in coastal areas and incorporate climate change impacts into natural disaster planning and management. 
It can be said that flooding in the coastal zone has typical sea-land characteristics. From the perspective of flood sources, floods in coastal zones are affected by factors such as storm surge and rising sea levels [7-12], while from the perspective of submerged land, the coastal zone is similar to the inland zone, and the submerging process is also affected by factors such as topography, land use, and building distribution [13-18]. Therefore, as the risk assessment of coastal zone marine disasters is based on flooding, it needs to be targeted to reflect these typical sea-land characteristics.

According to the literature, there has been relatively little research on the risk assessment of flooding disasters based on sea-land characteristics. Some of the studies only focused on the generation of flooding and considered cities as different kinds of sloping interfaces from the perspective of marine science [19-22]. And the RISC-KIT (resilience-increasing strategies for coasts-toolkit) index-method was applied in the Molise region, which takes the natural, social, and economic factors into consideration and focuses on the hazard and exposure indicators. Moreover, the dynamic models were coupled with the RISC-KIT index-method which paid attention to coastal vulnerability and risk from the perspective of the storm surge and sea level rise in England, Italy, Poland, and other countries [4,23-26]. Other research has addressed this topic from a terrestrial science perspective and focused on flooding caused by urban rivers and the impact of disaster losses, while ignoring the natural processes related to the unique source of flooding in coastal zones [20,23,27-29].

In contrast, the marine scientific method places more emphasis on studying the dynamic processes of increased water generation [30,31]. So for the simulation of flooding in marine disaster risk assessment, the marine science model can more accurately calculate the increasing storm surge process. Land science research has focused on the land interface process, which includes the submerging of ground structures and the loss brought by submergence [32]. In the process of submerging in inland areas [33], the land model is more accurate due to its comprehensive consideration of the coastline, dykes, land elevation, land-use types, and socio-economic conditions. Therefore, since the core part of the risk assessment is to comprehensively reflect the entire disaster process or disaster chain, it is important to combine the storm surge increase and land submergence in the calculation method.

The indicator system method is widely used in risk assessment because it can comprehensively reflect the influences of natural factors and social and economic factors in terms of risk. However, as natural data are difficult to obtain in the risk assessment process, most of the commonly used risk indicators are social and economic indicators, resulting in limited reflection of natural risk indicators, and thereby not showing the full degree of risk. For coastal cities, many factors influence marine flooding disasters. If natural processes or disaster chains can be reflected accurately, they can play significant roles in accurately describing the risk of disasters.

\subsection{Study Areas}

Qingdao is located on the southeast coast of the Shandong Peninsula in China [34], bordering the Yellow Sea (Figure 1). Affected by climate change, the characteristics of a maritime climate have become more prominent. Qingdao is affected by severe weather events such as typhoons and heavy rain throughout the year. Especially when typhoons cross, the combination of wind, storms, and tides can lead to a serious disaster. 


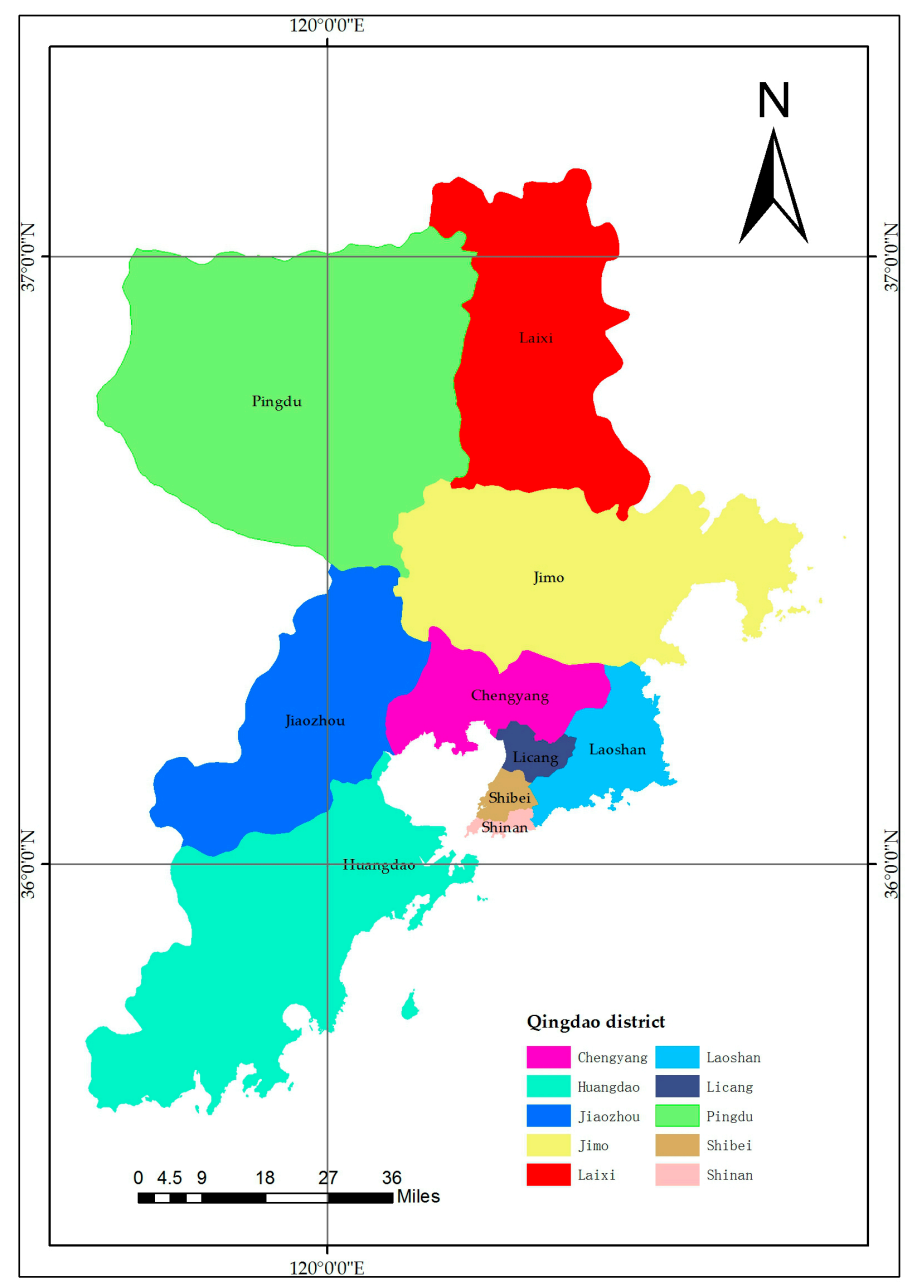

Figure 1. Map of Qingdao.

Regarding the Qingdao study area, the cause and effect sequence of a Qingdao marine disaster based on flooding is as follows: a typhoon causes a rainstorm and an increase in the wind field, which can affect the storm surge to some extent, and lead to extreme tide levels and an increase in water, thus causing a flooding-based marine disaster; at the same time, the rise in sea level will also cause an increase in basic water levels, which will result in the risk of flooding (Figure 2). 


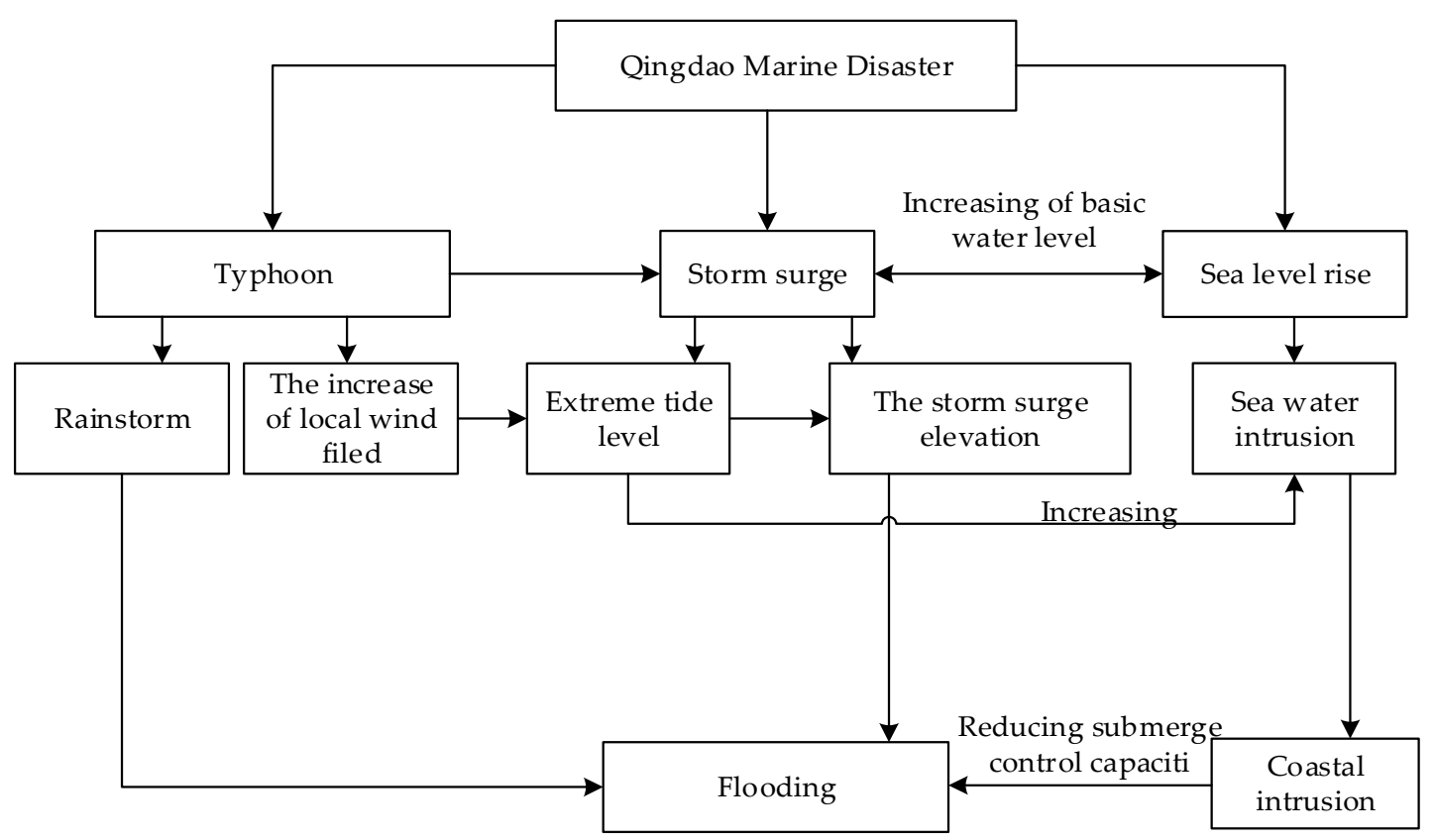

Figure 2. The cause and effects of Qingdao marine disaster based on flooding.

Qingdao is a member of C40 Cities Climate Leader Group, because of its important role in the climate adaption in the coastal cities. In addition, the case study was performed on Qingdao, a typical coastal city in Northern China, to build a risk assessment method for flooding in coastal zones with typical sea-land characteristics. Additionally, the study provides certain technical support for disaster prevention and mitigation in coastal zones worldwide.

\section{Materials and Methods}

Based on the characteristics of marine disaster risk due to flooding, this study combined the marine science and land science methods to obtain basic data indicators of the natural disaster chain and process of flooding in Qingdao through a survey and research results. A targeted indicator system based on the flooding risk of marine disasters was constructed and an effective assessment of the risk of marine disasters in Qingdao was carried out.

It should be noted that this paper focused on the risk assessment and main influencing factors of flooding-based marine disasters in Qingdao, and other marine disasters such as green tide (canola) and seawater intrusion were not considered.

\subsection{Typhoon}

According to the calculations of the Qingdao Meteorological Bureau, the eight typical typhoon types affecting Qingdao are as follows: landing north type (e.g., tf0509), landing turning type (e.g., tf0515), yellow sea west folding type (e.g., tf1105), offshore north type (e.g., tf1109), high latitude westward type (e.g., tf1210), far sea impact type (e.g., tf7308), landing padding type (e.g., tf7708), and offshore steering type (e.g., tf8114). The wind fields of these various types of typhoon in the four scenarios (current, 2025, 2035, and 2055) were calculated in turn, using the average central air pressure and central wind speed changes of the eight types of typhoon in the four scenarios (current, 2025, 2035, and 2055).

\subsection{Sea Level Rise}

The basic information related to sea level rise was obtained from the observation data of the No. 5 Qingdao Coastal Pier Monitoring Station and the Wheat Island Sites Monitoring Station. The calculations were based on the relevant dataset of the CMIP3 model (Coupled Model 
Intercomparison Project 3), and three commonly used greenhouse gas emission scenarios: B1, A1B, and $\mathrm{A} 2$. The $\mathrm{CO}_{2}$ concentration in the atmosphere and the $\mathrm{CO}_{2}$ equivalent emission concentration were also used in the calculation process. The coupled model of the ocean atmosphere and circulation was combined with the sea level change data of Qingdao under the background of climate change as follows: in the case of a temperature increase of $2{ }^{\circ} \mathrm{C}$, the sea level will rise by $4-10 \mathrm{~cm}(7 \pm 3)$, 8-16 cm (12 \pm 4$)$, and 14-28 cm (21 \pm 7$)$ in 2025, 2035, and 2055, respectively; in the case of warming by $4{ }^{\circ} \mathrm{C}$, the sea level will rise $5-11 \mathrm{~cm}(8 \pm 3), 10-18 \mathrm{~cm}(14 \pm 4)$, and 16-32 $\mathrm{cm}(24 \pm 8)$ in 2025,2035 , and 2055, respectively.

\subsection{Storm Surge}

The main factor leading to flooding in the coastal zone is storm surge, which is the main difference from flooding in inland cities. Therefore, accurate simulation of the natural storm surge process is the primary consideration for coastal flooding simulations.

Based on the characteristics of storm surge water increase in Qingdao, this paper selected the hydrodynamic calculation "ADCIRC" model (advanced circulation), which is a high-performance, cross-platform, numerical ocean circulation model that is popular for simulating storm surge, tides, and coastal circulation problems. The model uses the time-average continuous equation and motion equation along with the water depth integral to accurately portray the shoreline. On this basis, this study considered the eight types of typhoons affecting Qingdao and the average sea level rise in Qingdao for 2025, 2035, and 2055 (for increases of $2{ }^{\circ} \mathrm{C}$ and $4{ }^{\circ} \mathrm{C}$ in temperature). The meta-method was used to simulate the solution, and the basic equations of the storm surge were numerically solved in consideration of the well-defined boundary conditions and initial conditions in Qingdao. The storm surges were simulated under the tropical cyclone event set. All water level changes were calculated for the four scenarios (current, 2025, 2035, and 2055), three phases (at high tide, middle tide, and low tide), and eight types of typhoons (128 frequency in total). At the same time, the tidal water level changes in three phases and real conditions (32 frequency in total) were calculated. Based on the above steps, the spatial and temporal distribution of storm surge levels and storm currents in Qingdao were determined. It should be mentioned that the research area calculation grid was established with SMS (surface-water modeling system) meshing software.

\subsection{Submerging}

According to related research [35], the ground topographical changes of a coastal zone can have a great impact on storm surges, which are often only a few kilometers in magnitude. Therefore, in flood simulations, attention to topography and terrain is required.

The D8 Seed Spread Model is a functional model supported by ArcGIS software [36]. Its main function is to simulate submerging under different water levels according to the topography and distribution of buildings [37]. In this model, the input factors are as follows: storm water and floodplains affected by typhoons and sea level rise, coastline elevation, topography, land use extracted from a TM (thematic mapper) image, imperviousness, and building distribution as well as socio-economic data (obtained from the bulletin and literature data). After vectorization of the geographic information, the submerging range and land use were simulated according to the D8 Seed Spread Model (Figure 3). One of the key procedures of the D8 Seed Spread Model is to derive the hydrologic characteristics of a surface according to the topography, and then determine the direction of flow from every cell in the raster [38]. In the Qingdao study area, the D8 Seed Spread Model was used to eliminate the low elevation point areas far from the coastline and the annular zonal unconnected areas [39], such as hills and mountains, to predict the active flowing area. 


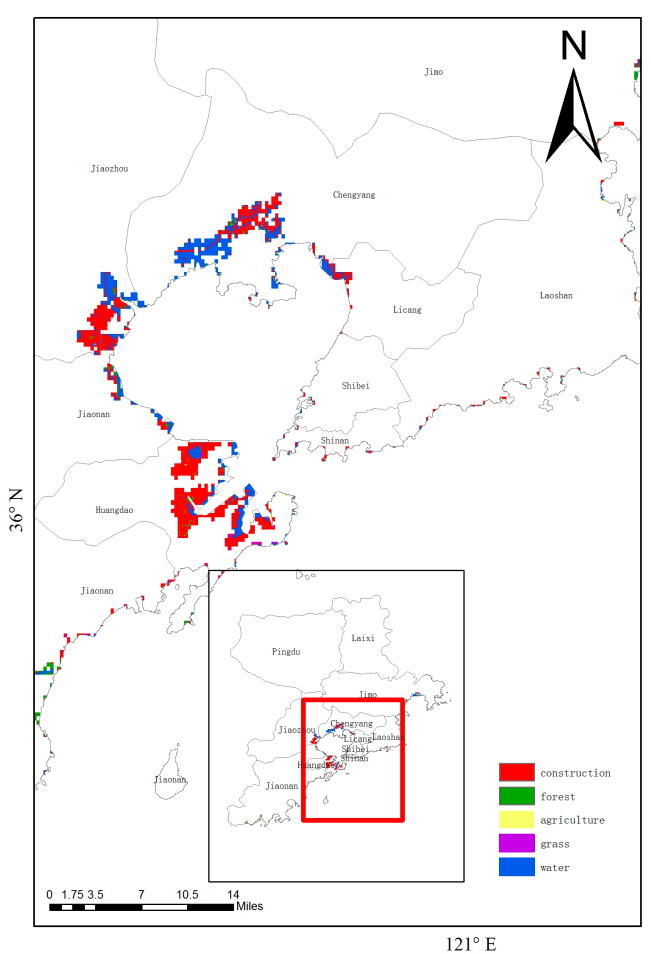

(a)

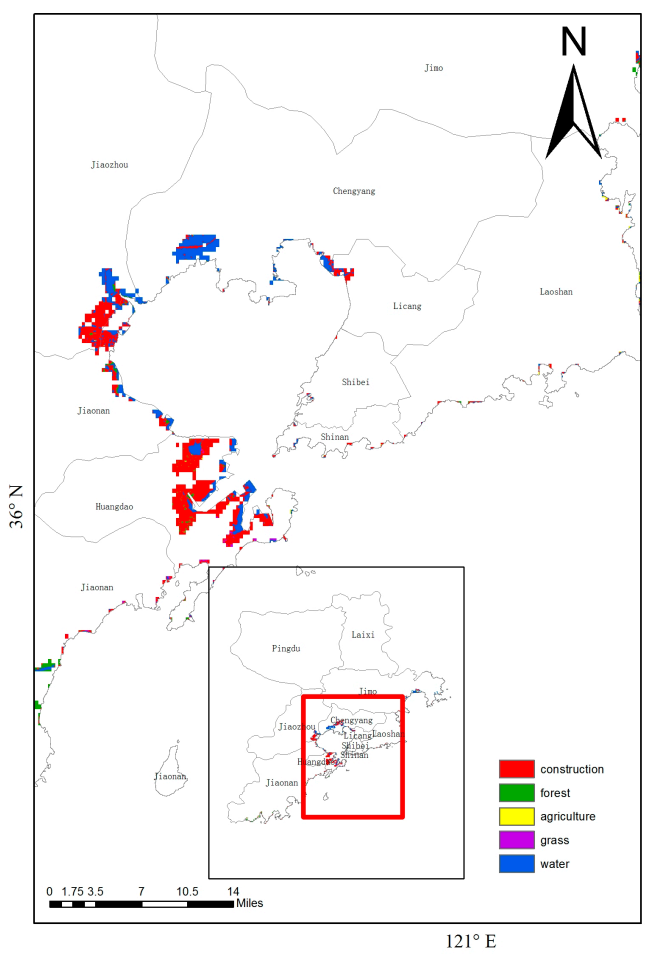

(c)

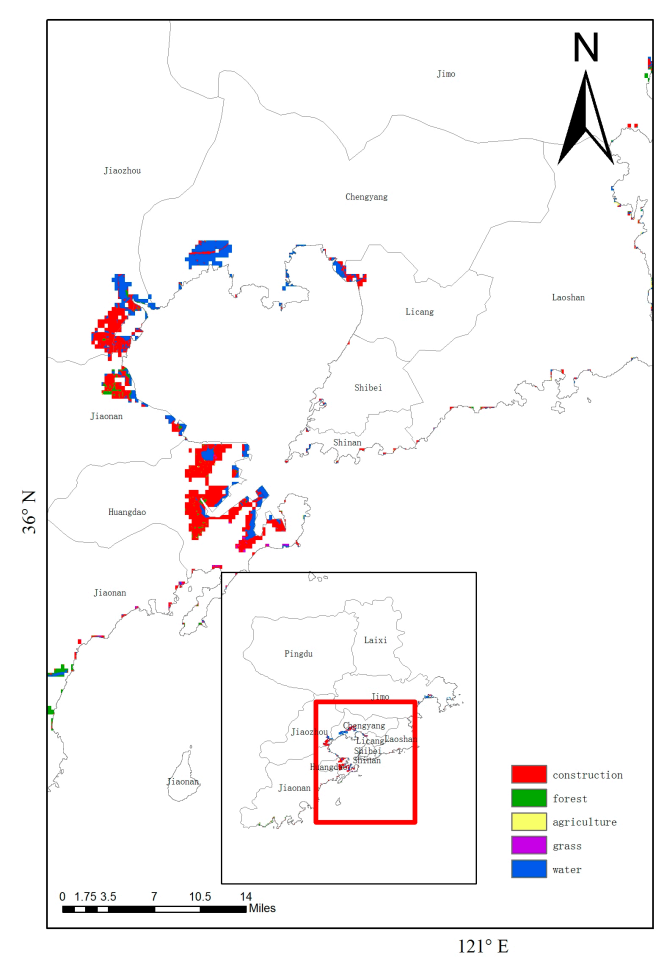

(b)

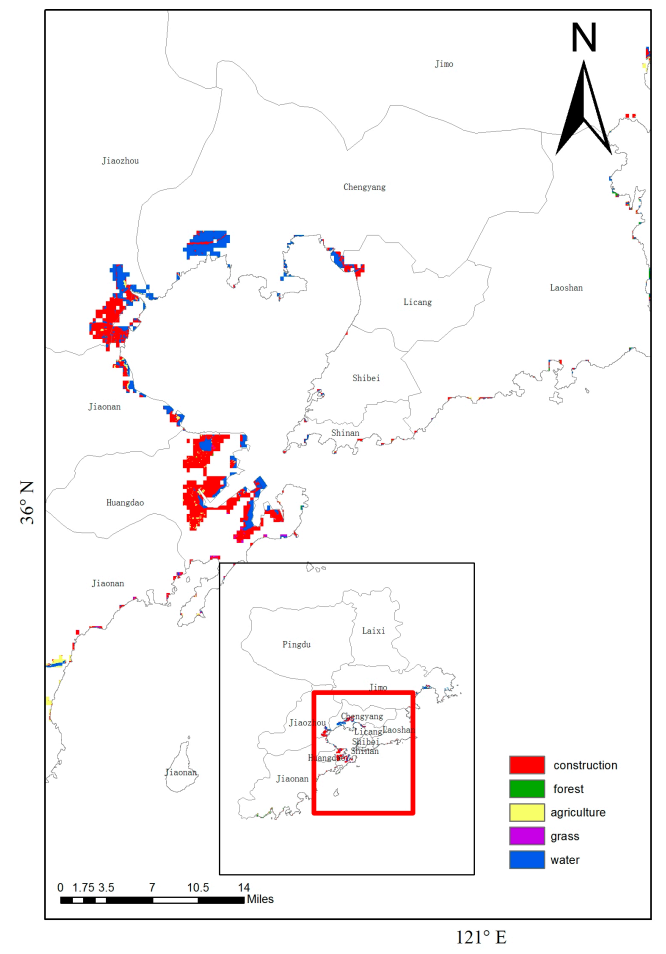

(d)

Figure 3. Cont. 


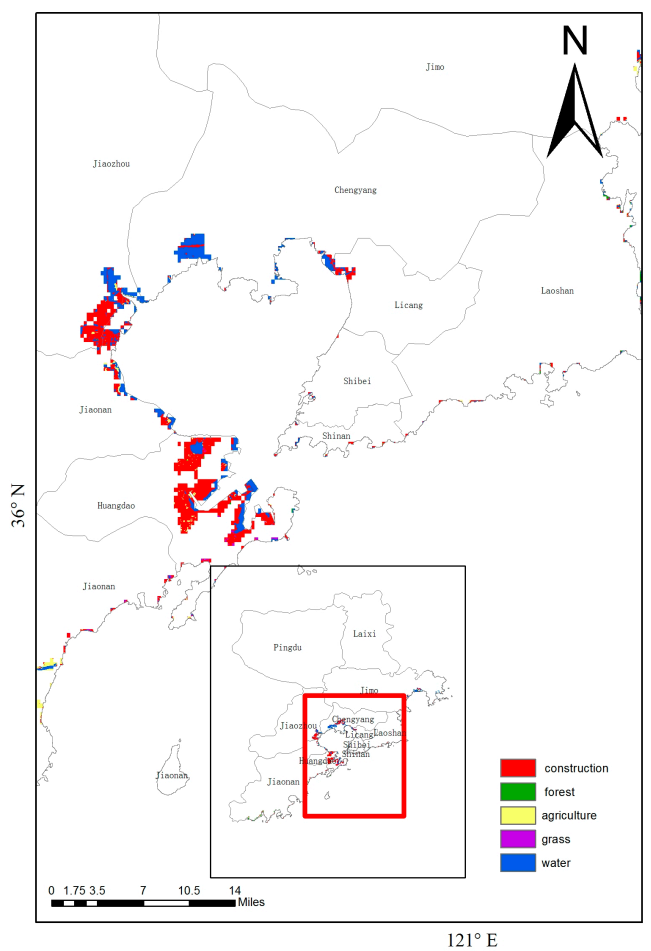

(e)

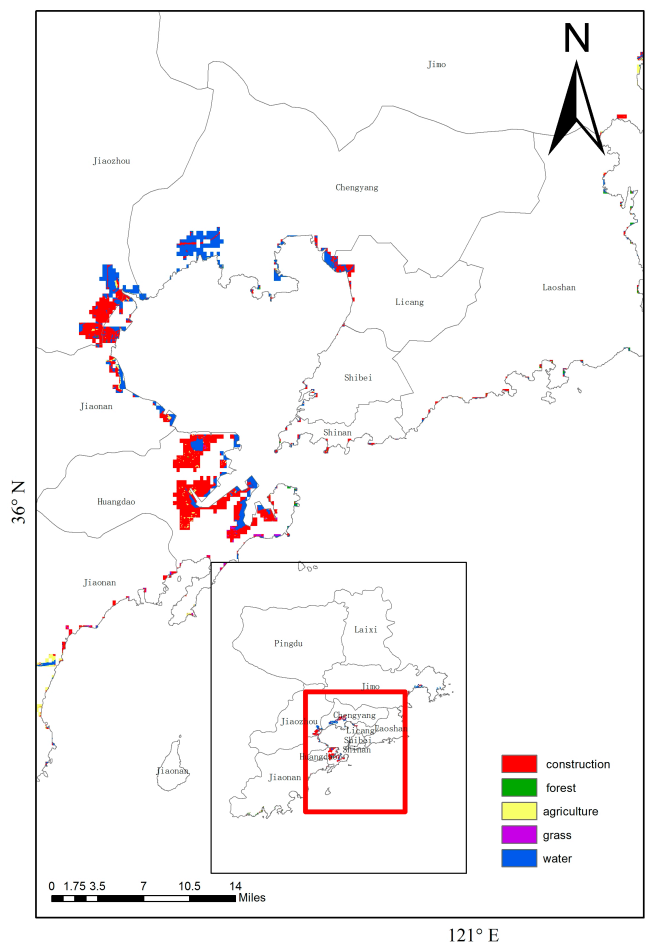

(g)

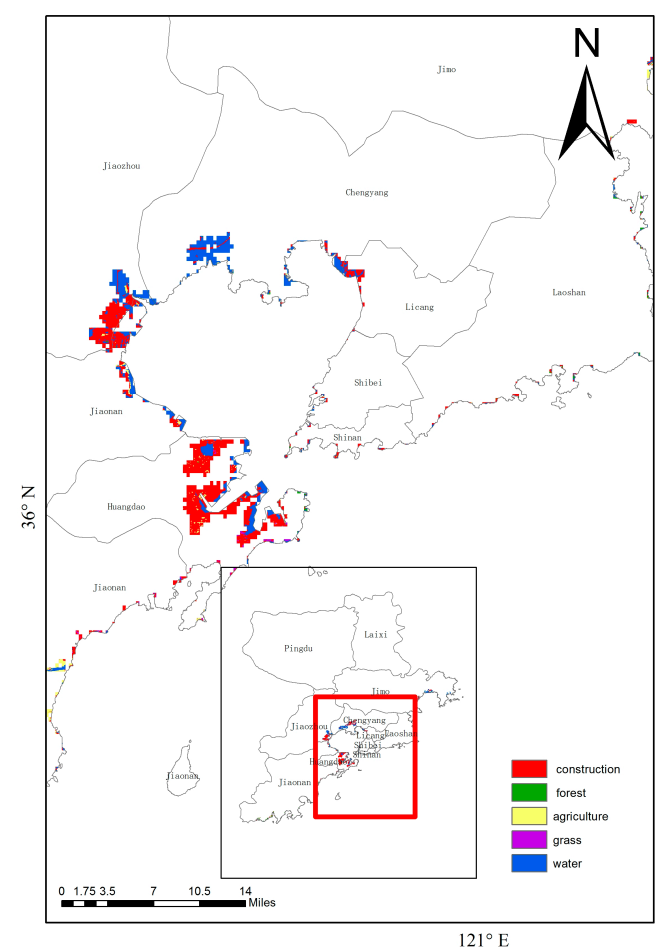

(f)

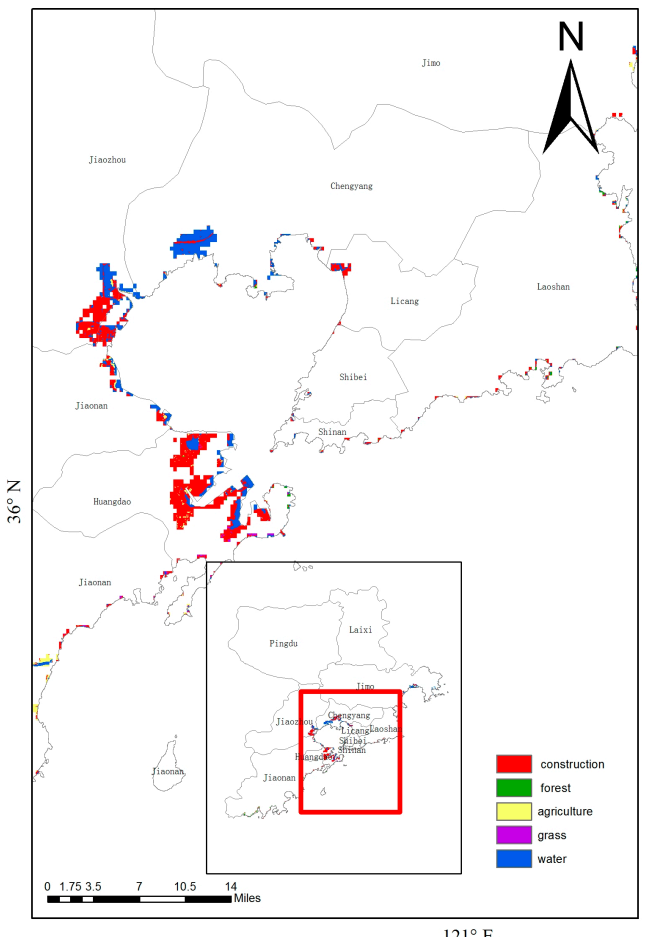

(h)

Figure 3. The submerging scope and land use of Qingdao under the influence of various types of typhoons. (a) Landing north type (e.g., tf0509); (b) landing turning type (e.g., tf0515); (c) Yellow Sea west folding type (e.g., tf1105); (d) offshore north type (e.g., tf1109); (e) far sea impact type (e.g., tf7308); (f) landing padding type (e.g., tf7708); (g) offshore steering type (e.g., tf8114); and (h) high latitude westward type (e.g., tf1210). 
The submerging area ratio and submerging area of the economic loss rate were estimated with the submerging scope and the economic loss price from the Qingdao Statistics Yearbook [34] (Table 1).

Table 1. The submerging area ratio and submerging area of the economic loss rate.

\begin{tabular}{ccccc}
\hline Land Use Types & $\begin{array}{c}\text { The Minimum } \\
\text { Submerging Area } \\
\text { Ratio }\end{array}$ & $\begin{array}{c}\text { The Maximum } \\
\text { Submerging Area of } \\
\text { Economic Loss Rate }\end{array}$ & $\begin{array}{c}\text { The Minimum } \\
\text { Submerging Area } \\
\text { Ratio }\end{array}$ & $\begin{array}{c}\text { The Maximum } \\
\text { Submerging Area of } \\
\text { Economic Loss Rate }\end{array}$ \\
\hline Construction land & $52.61 \%$ & $99.71 \%$ & $50.77 \%$ & $99.68 \%$ \\
Agriculture land & $10.92 \%$ & $0.02 \%$ & $9.20 \%$ & $0.01 \%$ \\
Forest land & $0.82 \%$ & $0.00 \%$ & $0.52 \%$ & $0.00 \%$ \\
Grass land & $0.95 \%$ & $0.00 \%$ & $0.80 \%$ & $0.00 \%$ \\
Water land & $38.20 \%$ & $0.30 \%$ & $36.28 \%$ & $0.28 \%$ \\
\hline
\end{tabular}

\subsection{Risk Assessment}

Based on the actual situation in Qingdao combined with our research results from the bulletin and literature data, this study built a targeted assessment indicator system of the flooding-based marine disaster risk in Qingdao, as shown in Table 2.

Based on the cause and effect sequence, the indicator system divides the factor layers into four parts: typhoon, sea level rise, storm surge, and submerging. Based on the risk composition [4,22], the first level is divided into the Hazard Index, the Vulnerability Index, and the Precaution Index.

In the first level, the Hazard Index refers to the risk source. In a climate system, risk occurs when abnormal processes or changes reach a certain threshold where the greater the degree of abnormality of the process or change is, the greater the risk [22]. The Vulnerability Index refers to and is symbolic of the risk carrier-humans and their social activities. The Precaution Index refers to the precautions and measures adopted by the risk carrier [22]. Additionally, the second and third level indicators are listed in turn, according to the characteristics of the first level indicators. From the classification of indicators, we can be seen that the Hazard Index mainly refers to natural factors, while the Vulnerability Index and Precaution Index include artificially controllable factors that can be controlled by humans.

Table 2. Assessment indicator system of the flooding-based marine disaster risk in Qingdao.

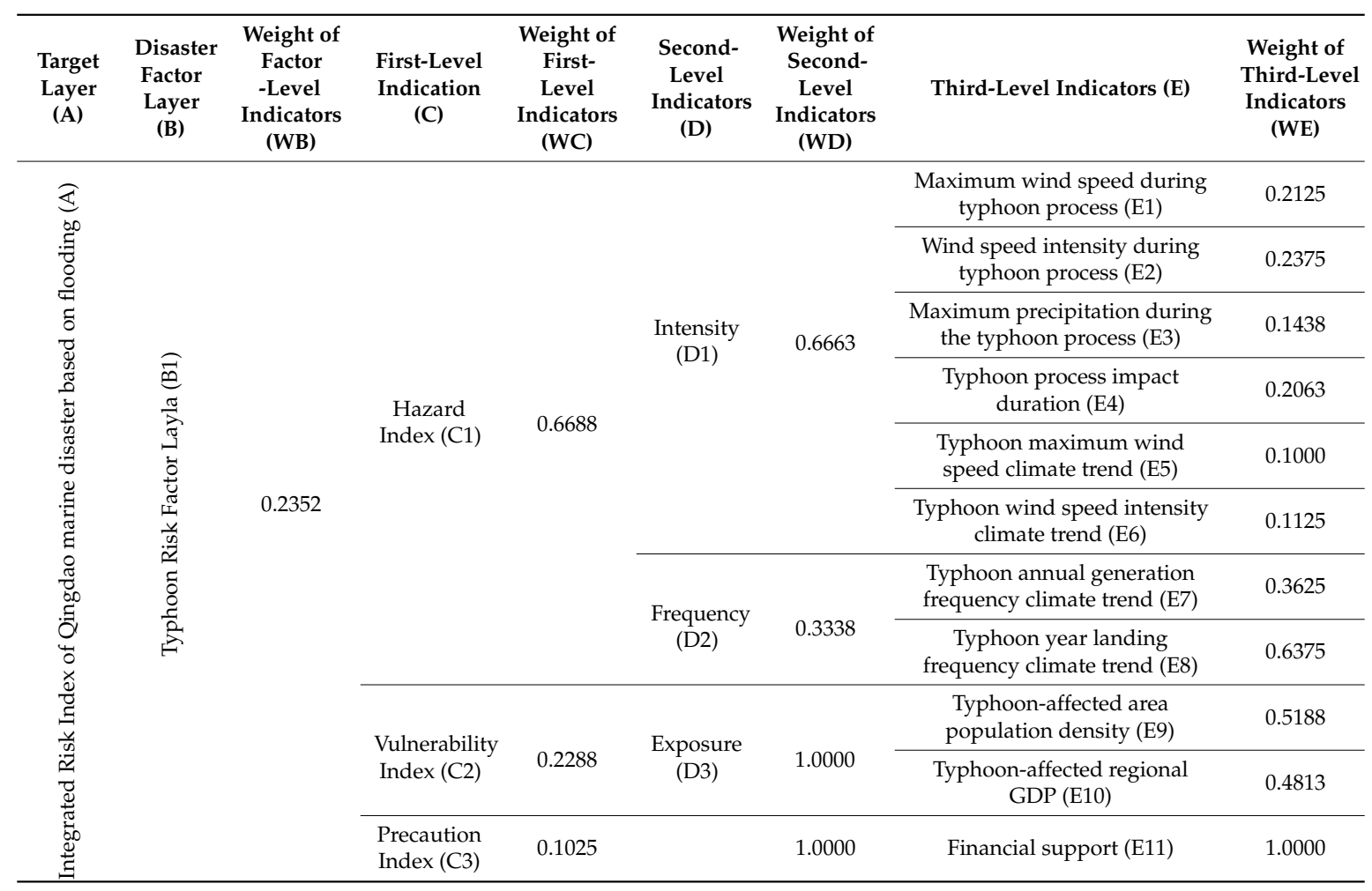


Table 2. Cont

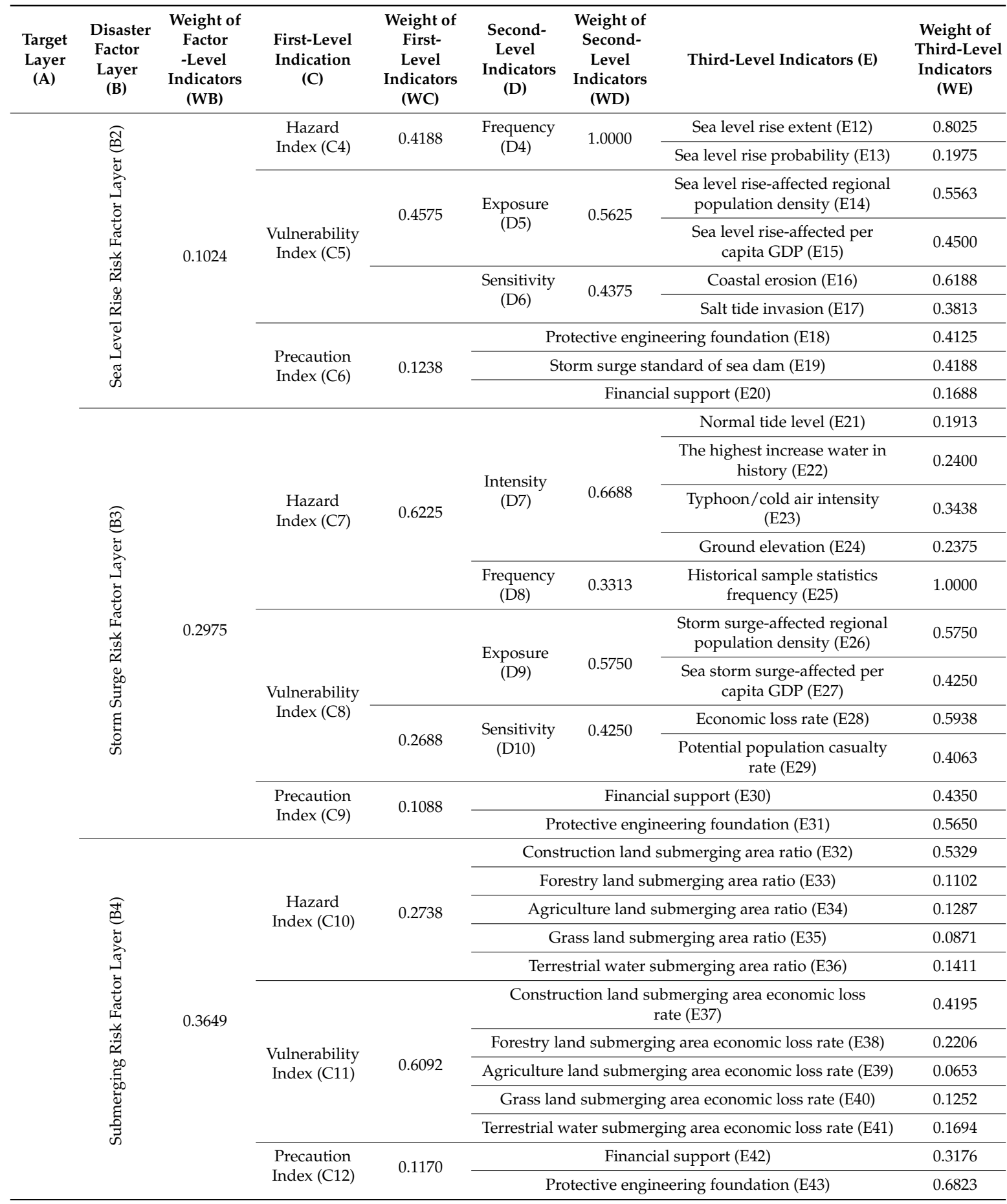

\subsubsection{Standardization of Indicators}

Since the dimensions of the different indicators are different, it is necessary to standardize them and convert them into dimensionless values between 0 and 1 . The standardized formula for all levels is as follows [4]:

$$
X_{i}=\frac{\left(x_{i}-X_{\text {min }}\right)}{\left(X_{\max }-X_{\min }\right)}
$$

where $X_{i}$ is the dimensionless value of the indicators; $x_{i}$ is the current values of the indicators; $X_{\max }$ is the maximum value of the indicators; and $X_{\min }$ is the minimum value of the indicators. 


\subsubsection{Determination of Weight}

Using the AHP (analytic hierarchy process) [40], expert scoring method [41], and comparison matrix method [42], a comparison matrix was constructed and the weights of the indicators were obtained at each level.

The comprehensive matrix method was used to determine the weights of the indicators. Matrix $\mathrm{B}$ was mutually influenced. The corresponding relationship between the $b_{i j}$ value and the relative importance of the indicators were defined as follows (Table 3):

$$
\mathrm{b}_{i j}>0 ; \mathrm{b}_{i j}=1 / \mathrm{b}_{j i} ; \text { and } \mathrm{b}_{i i}=1 \text {. }
$$

Table 3. Comparison matrix.

\begin{tabular}{ccccccc}
\hline $\mathbf{B}$ & $\mathbf{B}_{1}$ & $\mathbf{B}_{2}$ & $\ldots$ & $\mathbf{B}_{j}$ & $\ldots$ & $\mathbf{B}_{n}$ \\
\hline $\mathrm{B}_{1}$ & $\mathrm{~b}_{11}$ & $\mathrm{~b}_{12}$ & $\ldots$ & $\mathrm{b}_{1 j}$ & $\ldots$ & $\mathrm{b}_{1 n}$ \\
$\mathrm{~B}_{2}$ & $\mathrm{~b}_{21}$ & $\mathrm{~b}_{22}$ & $\ldots$ & $\mathrm{b}_{2 j}$ & $\ldots$ & $\mathrm{b}_{2 n}$ \\
$\ldots$ & $\ldots$ & $\ldots$ & $\ldots$ & $\ldots$ & & $\ldots$ \\
$\mathrm{B}_{i}$ & $\mathrm{~b}_{i 1}$ & $\mathrm{~b}_{i 2}$ & $\ldots$ & $\mathrm{b}_{i j}$ & $\ldots$ & $\mathrm{b}_{i n}$ \\
$\ldots$ & $\ldots$ & $\ldots$ & & $\ldots$ & & $\ldots$ \\
$\mathrm{B}_{n}$ & $\mathrm{~b}_{n 1}$ & $\mathrm{~b}_{n 2}$ & $\ldots$ & $\mathrm{b}_{n j}$ & $\ldots$ & $\mathrm{b}_{n n}$ \\
\hline
\end{tabular}

In this study, the following relations were used:

$\mathrm{B}_{\mathrm{i}}$ is as important as $\mathrm{B}_{j}, \mathrm{~b}_{i j}=1, \mathrm{~b}_{j i}=1$

$\mathrm{B}_{\mathrm{i}}$ is slightly more important than $\mathrm{B}_{j}, \mathrm{~b}_{i j}=3, \mathrm{~b}_{j i}=1 / 3$

$B_{i}$ is obviously more important than $B_{j}, b_{i j}=5, b_{j i}=1 / 5$

$\mathrm{B}_{\mathrm{i}}$ is more important than $\mathrm{B}_{j}, \mathrm{~b}_{i j}=7, \mathrm{~b}_{j i}=1 / 7$

$B_{i}$ is much more important than $B_{j}, b_{i j}=9, b_{j i}=1 / 9$

If the relative importance of the compared elements is between the above two adjacent judgments, $\mathrm{b}_{i j}=2,4,6,8, \mathrm{~b}_{j i}=1 / 2,1 / 4,1 / 6,1 / 8$.

\subsubsection{Calculation of Integrated Risk Index}

The Integrated Risk Index and Contribution Rate are as follows [4,22]:

$$
\text { IRI }=H \cdot V \cdot(1-P)
$$

where IRI is the Integrated Risk Index; $H$ is the Hazard Index; $V$ is the Vulnerability Index; and $P$ is the Precaution Index.

When IRI is between $(0,1)$, the greater the IRI is, the greater the risk is $(4,22)$.

$$
\mathrm{CR}=\frac{E W}{\mathrm{IRI}} * 100 \%
$$

where CR is the Contribution Rate; IRI is the Integrated Risk Index; $E$ is the value of the indicators; and $W$ is the weight of the indicators.

\section{Results and Analysis}

\subsection{Comprehensive Assessment of Marine Disaster Risk}

The data from the comprehensive assessment are shown in Table 4. 
Table 4. Integrated Risk Index of flooding-based marine disasters in Qingdao.

\begin{tabular}{cccccc}
\hline Disaster Factor Layer & $\begin{array}{c}\text { Hazard } \\
\text { Index }\end{array}$ & $\begin{array}{c}\text { Vulnerability } \\
\text { Index }\end{array}$ & $\begin{array}{c}\text { Precaution } \\
\text { Index }\end{array}$ & Risk Value & $\begin{array}{c}\text { Contribution } \\
\text { Rate }\end{array}$ \\
\hline Typhoon Risk (B1) & 0.4397 & 0.1957 & 0.3176 & 0.3822 & $24.34 \%$ \\
Sea Level Rise Risk (B2) & 0.0396 & 0.2985 & 0.3455 & 0.1412 & $3.91 \%$ \\
Storm Surge Risk (B3) & 0.3874 & 0.2052 & 0.2512 & 0.3509 & $28.26 \%$ \\
Submerging Risk (B4) & 0.4000 & 0.4198 & 0.2934 & 0.4403 & $43.49 \%$ \\
Integrated Risk Index (A) & & & 0.3694 & & \\
\hline
\end{tabular}

The Integrated Risk Index classification is shown in Table 5 [22].

Table 5. The Integrated Risk Index (IRI) classification of marine natural disaster risk in China.

\begin{tabular}{cccccc}
\hline IRI Range & $<\mathbf{0 . 1 1}$ & $\mathbf{0 . 1 1 - 0 . 2 9}$ & $\mathbf{0 . 2 9 - 0 . 5 0}$ & $\mathbf{0 . 5 0 - 0 . 6 8}$ & $>\mathbf{0 . 6 8}$ \\
\hline \multirow{2}{*}{ Classification } & 1 & 2 & 3 & 4 & 5 \\
& Lower risk & Low risk & Middle risk & High risk & Higher risk \\
\hline
\end{tabular}

According to the assessment indicator system, the Integrated Risk Index (A) for the flooding-based marine disaster risk in Qingdao (Table 4), was calculated to have a value of 0.3694 . Referring to the classification of natural disasters in China's major coastal areas (Table 5), the rating of the risk to Qingdao is 3, which is in the medium risk level. We can see that the Hazard Index and Vulnerability Index contribution rates were high, where the Hazard Index refers to more natural factors and the Vulnerability Index represents both natural factors and human factors.

Through the analysis of the contribution rate of each first-level index to the four types of disaster factors, it can be concluded that: (1) the Hazard Index is positively correlated with the risk value of the disaster factors, that is, the greater the Hazard Index, the higher the disaster factor level value. For example, typhoon is the strongest risk of the four disaster factors. (2) There is a positive correlation between the Vulnerability Index and the risk value of the disaster factor layer, for example, the Vulnerability Index of the Flooding Risk Factor Layer (C11) was much higher than that of the Sea Level Rise Risk Factor Layer, the Storm Surge Risk Factor Layer (C5), and the Typhoon Risk Factor Layer (C2), so the Flooding Risk Factor Layer (B4) was the highest. (3) The Precaution Index has a negative correlation with the risk value of the disaster factor layer, that is to say, the stronger the Precautionary Index is, the smaller the risk value of each disaster factor layer.

Among the third-level indicators (Figure 4), the order of Contribution Rate of the Integrated Risk Index Factors to the marine risk from highest to lowest was as follows: Wind speed intensity during The typhoon process (E2); Maximum wind speed during the typhoon process (E1); Typhoon process impact duration (E4); Coastal erosion (E16); Sea level rise extent (E12); Ground elevation (E24); The highest increase in water in history (E22); Typhoon/cold air intensity (E23); Construction land submerging area economic loss rate (E37); Terrestrial water submerging area economic loss rate (E41); and Construction land submerging area ratio (E32). 


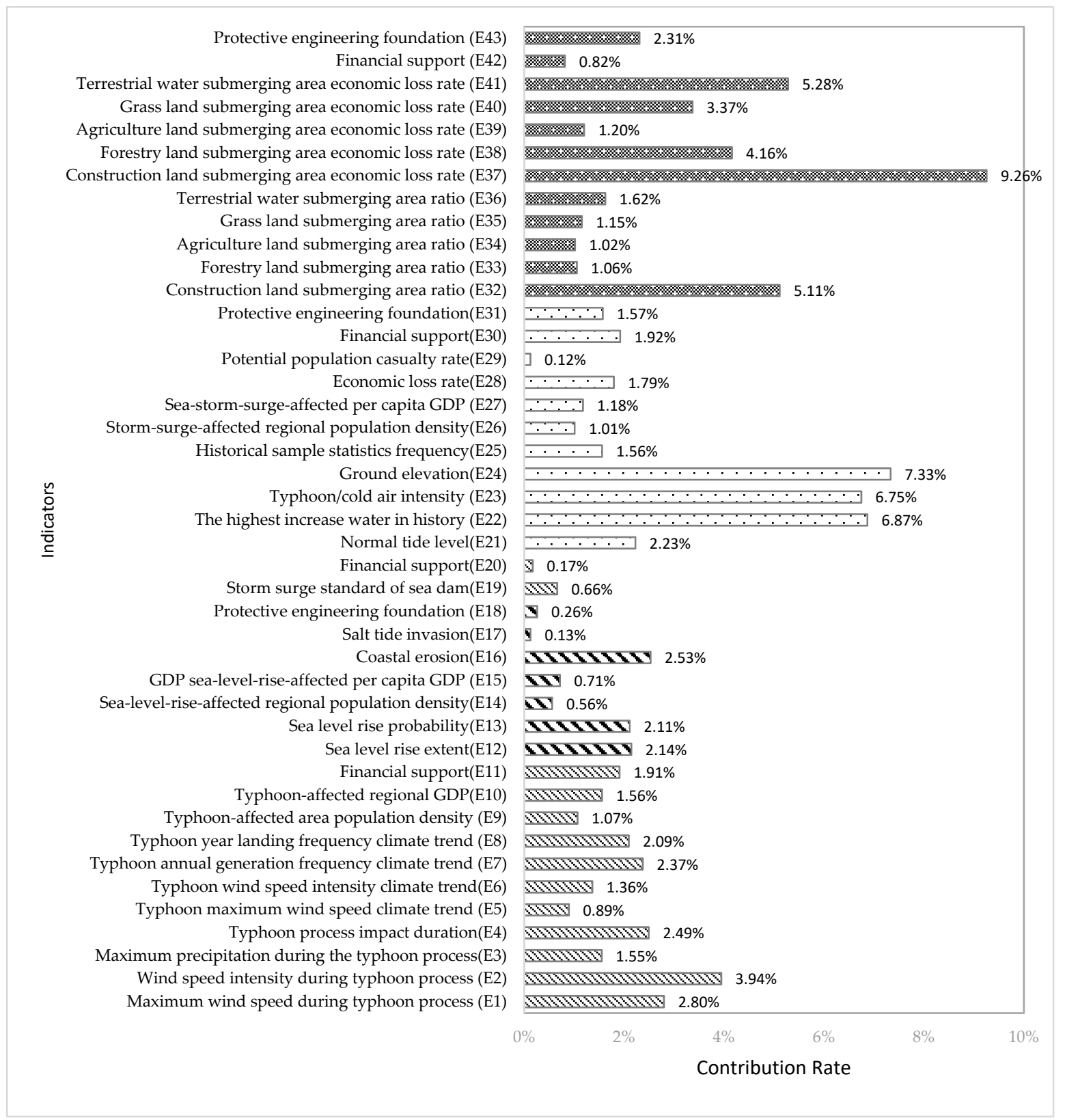

Figure 4. The contribution rates of the third-level indicators of the flooding-based marine disaster risk in Qingdao.

\subsection{Flooding Risk Factor Layer}

The Flooding Risk Factor Layer (B4) was 0.4403 , and the contribution rate to the Integrated Risk Index (A) was $43.49 \%$; this was shown to be the most important risk factor layer.

Among the first-level indicators of the Flooding Risk Factor Layer, the Flooding Risk Factor Layer (B4) was positively correlated with the Hazard Index (0.4000) (C10) and the Vulnerability Index (0.4198) (C11) - the larger the values for the two indexes were, the larger the Flooding Risk Factor Layer (B4). The Flooding Risk Factor Layer (B4) was negatively correlated with the Precaution Index (0.2934) (C12). If the Precaution Index (C12) was weak, the Flooding Risk Factor Layer (B4) was high.

Among the third-level indicators of the Flooding Risk Factor Layer (B4), the Construction land submerging area economic loss rate (E37) (9.26\%), Terrestrial water submerging area economic loss rate (E41) $(5.28 \%)$, and Construction land submerging area ratio (E32) $(5.11 \%)$ had the three highest contribution rates. According to the submerging map, submerging construction land mainly included 
residential land, public facilities, and enterprises. In terms of the submerging terrestrial water, the marine aquaculture industry in Qingdao was shown to be mostly distributed in this area, which will cause more economic losses than flooding in the agricultural land, forestry, and grassland in the same area.

\subsection{Storm Surge Risk Factor Layer}

Once combined with the astronomical tide, the north-orienting typhoon affecting Qingdao City is prone to storm surge disasters. In recent years, Qingdao has suffered one or two storm surges in almost every year.

The risk value of the Storm Surge Risk Factor Layer (B3) was 0.3509, and the contribution rate to the Integrated Risk Index (A) was 28.26\%. Regarding the first-level Storm Surge Risk Factor Layer (B3), the Hazard Index (C7), and Vulnerability Index (C8) of the storm surge were higher, but the Precaution Index (C9) was weak.

Among the third-level indicators of the Storm Surge Risk Factor Layer (B3), the Ground elevation (E24), The highest increase water in history (E22), and the Typhoon/cold air intensity (E23) were the most important indicators contributing to the Integrated Risk Index (A), with contribution rates of $7.33 \%, 6.87 \%$, and $6.75 \%$, respectively. According to the correlation analysis, it can be concluded that the higher the Ground elevation (E24) is, the smaller the impact of the storm surge. The highest increase in water in history (E22) had a certain correlation with the possibility of water increasing during storm surge, and Typhoon/cold air intensity (E23) showed a certain positive correlation with the risk of a storm surge.

\subsection{Typhoon Risk Factor Layer}

According to the statistics of storm surge disasters in Qingdao from 1898 to 2017, about 150 typhoons affected Qingdao City during that time period. North-orienting typhoons (mainly involving land-turning, landing-north, offshore-north, and north-orienting Yellow Sea) were the main causes of the storm surge affecting Qingdao offshore. The typhoon statistics of Qingdao over the years show that the average wind speed intensity index (the average value of typhoon intensity in each typhoon) affecting Qingdao was between 3.21 and 4.27, and the maximum wind speed during the typhoon reached $47 \mathrm{~m} / \mathrm{s}$ (the average maximum wind speed of the typhoons).

For the first-level risk factors, the Typhoon Risk Factor Level Index (B1) was 0.3822, and the contribution rate to the Integrated Risk Index (A) was $24.34 \%$. For the third-level indicators of the Typhoon Risk Factor Level Index (B1), the Wind speed intensity during typhoon process (E2) and the Maximum wind speed during the typhoon process (E1), and the Typhoon process impact duration (E4) were the three most important indicators of this type of disaster. As the above three indicators characterize the intensity and duration of the typhoon, the greater their values are, the higher the value of the Typhoon Risk Factor Level Index (B1).

\subsection{Sea Level Rise Risk Factor Layer}

The main impact of sea level rise is an increase in the basic water level of the sea, which will have increased flooding risk in the case of storm surges. In the Integrated Risk Index (A) of Qingdao, the value of Sea Level Rise Risk Factor Layer was 0.1412 (B2), and the contribution rate was the lowest (3.91\%).

Among the first-level indicators of the Sea Level Rise Risk Factor Layer, the Hazard Index (C4) was 0.0396 and the Precaution Index (C6) was 0.3455. Among the nine third-level indicators in this layer, Coastal erosion (E16) and Sea level rise extent(E12) were the key factors affecting the risk of sea level rise, and the contribution rates to the Integrated Risk Index (A) were $2.53 \%$ and $2.14 \%$, respectively.

It should be noted that although the contribution of sea level rise to Qingdao's marine disaster risk is comparatively small at present, the obvious upward trend of the sea level under climate change 
will affect the integrated risk of marine disasters in Qingdao in the long-term. Therefore, this is also a hazard factor that cannot be ignored in future formulations of the adaptation policy.

\section{Conclusions and Discussion}

\subsection{Conclusions}

The fundamental purpose of risk assessment is to quantify the risk and influential factors. As a result of climate change, disasters and disaster chain systems brought about by uncontrollable natural factors are becoming more dramatic. Therefore, only by clarifying the natural processes of disasters, can we effectively identify the risk of disasters occurring. By replacing passive responses with proactive adaption, the adverse effects for the ecosystem and human society can be reduced. Flooding-based marine disasters have had a large negative impact on Qingdao, and this is predicted to show an increasing trend under climate change. Based on a large amount of first-hand survey data, starting with the natural process of disasters, this paper built on the targeted flood-based marine disaster risk assessment indicator system. According to a comprehensive evaluation, we conclude that the indicators with large contribution rates were almost all natural. This indicates that the natural disaster process and disaster chain greatly affect the flooding disaster risk in Qingdao, while artificial control work (reflected by the Precaution Index) has a relatively low effect on reducing the disaster risk. From the perspective of the evaluation method, as this paper focused on the disaster from natural processes and risk chains, it can be concluded that natural factors still play an absolute and important role in disaster, which cannot be revealed by the general risk assessment indicator system (which only pays attention to the economic loss). However, despite this, the preventive methods implemented by humans can still have a positive effect on disaster reduction. Therefore, human society should continue to develop its understanding of disasters caused by natural processes, change its passive responses to active adaptation, and actively strengthen preventive measures to alleviate the adverse impact of increasingly serious natural disasters.

\subsection{Discussion}

Due to the limitations of the indicator system method, the uncertainty of the model could not be obtained, and the results will have different indicators and weights. However, the attempt to integrate and quantify various natural and human controllable factors provides certain technical support for disaster prevention and mitigation in coastal zones.

Author Contributions: All authors made great contributions to this article. G.Y., Q.L. (Qi Liao), and C.L. put forward the conceptualization, methodology, writing, and used the software to finish the calculations. Formal analysis was carried out by all authors. W.J. proposed the invaluable conceptualization and investigation for the whole paper. The typhoon and sea level rise data were provided by Y.M. and K.L.

Funding: This research was funded by the ACCCII Project (Adapting to Climate Change in China Phase II Qingdao Pilot), which complies with the Swiss federal administration corporate design guidelines.

Acknowledgments: All authors are grateful to Paul Sayers at Oxford University, who provided us with valuable suggestions.

Conflicts of Interest: The authors declare no conflict of interest.

\section{References}

1. Mach, K.J.; Mastrandrea, M.D.; Bilir, T.E.; Field, C.B. Understanding and responding to danger from climate change: The role of key risks in the IPCC AR5. Clim. Chang. 2016, 136, 427-444. [CrossRef]

2. Hay, J.; Mimura, N. The changing nature of extreme weather and climate events: Risks to sustainable development. Geomat. Nat. Hazards Risk 2010, 1, 3-18. [CrossRef]

3. Martinelli, L.; Zanuttigh, B.; Corbau, C. Assessment of coastal flooding hazard along the Emilia Romagna littoral, IT. Coast. Eng. 2010, 57, 1042-1058. [CrossRef] 
4. Aucelli, P.P.; Di Paola, G.; Rizzo, A.; Rosskopf, C.M. Present day and future scenarios of coastal erosion and flooding processes along the Italian Adriatic coast: The case of Molise region. Environ. Earth Sci. 2018, 77, 371. [CrossRef]

5. Shi, P.; Xu, W.; Ye, T.; He, C.; Wang, J.; Li, N. Developing disaster risk science. J. Nat. Disaster Sci. 2011, 32, 79-88. [CrossRef]

6. Feng, X.; Tsimplis, M.N. Sea level extremes at the coasts of China. J. Geophys. Res. 2014, 119, $1593-1608$. [CrossRef]

7. Fang, Y.; Yin, J.; Wu, B. Flooding risk assessment of coastal tourist attractions affected by sea level rise and storm surge: A case study in Zhejiang Province, China. Nat. Hazards 2016, 84, 611-624. [CrossRef]

8. Sayers, P.; Penning-Rowsell, E.C.; Horritt, M. Flood vulnerability, risk, and social disadvantage: Current and future patterns in the UK. Reg. Environ. Chang. 2018, 18, 339-352. [CrossRef]

9. Bhattacharya, T.; Guleria, S. Coastal flood management in rural planning unit through land-use planning: Kaikhali, West Bengal, India. J. Coast. Conserv. 2012, 16, 77-87. [CrossRef]

10. Bieri, M.; Schleiss, A. Analysis of flood-reduction capacity of hydropower schemes in an A lpine catchment area by semidistributed conceptual modelling. J. Flood Risk Manag. 2013, 6, 169-185. [CrossRef]

11. Dostal, P.; Imbery, F.; Bürger, K.; Seidel, J. Regional determination of historical heavy rain for reconstruction of extreme flood events. In Extremis; Springer: Berlin, Germany, 2011; pp. 90-102.

12. Friedman, J.M.; Lee, V.J. Extreme floods, channel change, and riparian forests along ephemeral streams. Ecol. Monogr. 2002, 72, 409-425. [CrossRef]

13. Kirshen, P.; Knee, K.; Ruth, M. Climate change and coastal flooding in Metro Boston: Impacts and adaptation strategies. Clim. Chang. 2008, 90, 453-473. [CrossRef]

14. Villatoro, M.; Silva, R.; Méndez, F.; Zanuttigh, B.; Pan, S.; Trifonova, E.; Losada, I.; Izaguirre, C.; Simmonds, D.; Reeve, D. An approach to assess flooding and erosion risk for open beaches in a changing climate. Coast. Eng. 2014, 87, 50-76. [CrossRef]

15. Hinkel, J.; Jaeger, C.; Nicholls, R.J.; Lowe, J.; Renn, O.; Peijun, S. Sea-level rise scenarios and coastal risk management. Nat. Clim. Chang. 2015, 5, 188. [CrossRef]

16. Peng, J.; Wei, H.; Wen, U. Storm flood disaster risk assessment in urban area based on the simulation of land use scenarios: A case of maozhou watershed in Shenzhen city. Acta Ecol. Sin. 2018, 38, 3741-3755. [CrossRef]

17. Wetter, O.; Pfister, C.; Weingartner, R.; Luterbacher, J.; Reist, T.; Trösch, J. The largest floods in the high rhine basin since 1268 assessed from documentary and instrumental evidence. Hydrol. Sci. J. 2011, 56, 733-758. [CrossRef]

18. Yoon, S.-K.; Kim, J.-S.; Moon, Y.-I. Integrated flood risk analysis in a changing climate: A case study from the Korean Han River Basin. KSCE J. Civ. Eng. 2014, 18, 1563-1571. [CrossRef]

19. Simonović, S.P. Floods in a Changing Climate: Risk Management; Cambridge University Press: Cambridge, UK, 2012.

20. Merz, B.; Aerts, J.; Arnbjerg-Nielsen, K.; Baldi, M.; Becker, A.; Bichet, A.; Blöschl, G.; Bouwer, L.; Brauer, A.; Cioffi, F. Floods and climate: Emerging perspectives for flood risk assessment and management. Nat. Hazards Earth Syst. 2014, 2, 1559-1612. [CrossRef]

21. Takagi, H.; Tsurudome, C.; Thao, N.D.; Le, T.A.; Van Ty, T.; Van, P.D.T. Ocean tide modelling for urban flood risk assessment in the Mekong Delta. Hydrol. Res. Lett. 2016, 10, 21-26. [CrossRef]

22. Zhang, R.; Ge, S.; Hong, M.; Li, Q. Climate Change and National Marine Strategy-Influence and Risk Assessment; China Meteorological Press: Beijing, China, 2013; pp. 208-223, ISBN 978-7-50-295877-0.

23. Merz, B.; Aerts, J.; Arnbjerg-Nielsen, K.; Baldi, M.; Becker, A.; Bichet, A.; Blöschl, G.; Bouwer, L.; Brauer, A.; Cioffi, F. Floods and climate: Emerging perspectives for flood risk assessment and management. Nat. Hazards Earth Syst. Sci. 2014, 14, 1921-1942. [CrossRef]

24. Lieske, D.J.; Wade, T.; Roness, L.A. Climate change awareness and strategies for communicating the risk of coastal flooding: A Canadian maritime case example. Estuar. Coast. Shelf Sci. 2014, 140, 83-94. [CrossRef]

25. Idier, D.; Rohmer, J.; Bulteau, T.; Delvallée, E. Development of an inverse method for coastal risk management. Nat. Hazards Earth Syst. 2013, 13, 999-1013. [CrossRef]

26. Goeldner-Gianella, L.; Bertrand, F. Managing coastal flooding risk through depolderisation: Perceptions of local stakeholders and implementation of public policies in the Arcachon Bay (France). Nat. Sci. Soc. 2014, 22, 219-230. [CrossRef] 
27. Li, J.; Tan, S. Nonstationary flood frequency analysis for annual flood peak series, adopting climate indices and check DAM index as covariates. Water Resour. Manag. 2015, 29, 5533-5550. [CrossRef]

28. Saud, M.A. Flood Control Management for the City and Surroundings of Jeddah, Saudi Arabia; Springer: Berlin, Germany, 2015; Volume 2, pp. 33-43. [CrossRef]

29. Day, G.; Dietrich, W.E.; Rowland, J.C.; Marshall, A. The depositional web on the floodplain of the Fly River, Papua New Guinea. J. Geophys. Res. 2008, 113, F01S2. [CrossRef]

30. Elliott, M. Integrated marine science and management: Wading through the morass. Mar. Pollut. Bull. 2014, 86, 1-4. [CrossRef]

31. Glover, D.M.; Jenkins, W.J.; Doney, S.C. Modeling Methods for Marine Science; Cambridge University Press: Cambridge, UK, 2011. [CrossRef]

32. Messina, J.P.; Pan, W.K. Different ontologies: Land change science and health research. Curr. Opin. Environ. Sustain. 2013, 5, 515-521. [CrossRef]

33. Nyman, J.; De Laune, R.; Pezeshki, S.; Patrick, W. Organic matter fluxes and marsh stability in a rapidly submerging estuarine marsh. Estuaries 1995, 18, 207-218. [CrossRef]

34. QBSC. Yearbook of Qingdao in 2018. 2018. Available online: http://www.stats-qd.gov.cn/n28356045/ n32561056/n32561073/n32565483/index.html (accessed on 17 October 2018).

35. Jiang, W.; Wu, D.; Gao, H. The observation and simulation of bottom circulation in the Bohai Sea in summer. J. Ocean Univ. Qingdao 2002, 32, 511-518. [CrossRef]

36. Zhao, X.; Wang, Y.; Li, H.; Zhang, D. Design and implementation of seed spread algorithm for calculations of source flood submerge area based on DEM. Sci. Technol. Rev. 2012, 30, 61-64. [CrossRef]

37. Zhang, D.H.; Liu, R.; Zhang, Y.X.; Xie, J.H. The design and implement of a new algorithm to calculate source flood submerge area based on DEM. J. East China Inst. Technol. 2009, 32, 183-184. [CrossRef]

38. Li, K.; Cao, J.; Li, S.; Chen, S. Study of catchment and submerging analysis based on DEM. J. Shandong Univ. Technol. 2013, 27, 26-28. [CrossRef]

39. Rainer, J.M. Submerging or clinging on again? Jozsef antall, father and son, in hungary after 1956. Contemp. Eur. Hist. 2005, 14, 65-105. [CrossRef]

40. Saaty, T.L. Decision making with the analytic hierarchy process. Int. J. Serv. Sci. 2008, 1, 83-98. [CrossRef]

41. Kwong, C.K.; Ip, W.H.; Chan, J.W. Combining scoring method and fuzzy expert systems approach to supplier assessment: A case study. Integr. Manuf. Syst. 2002, 13, 512-519. [CrossRef]

42. Wang, Y.; Elhag, T. A goal programming method for obtaining interval weights from an interval comparison matrix. Eur. J. Oper. Res. 2007, 177, 458-471. [CrossRef]

(C) 2019 by the authors. Licensee MDPI, Basel, Switzerland. This article is an open access article distributed under the terms and conditions of the Creative Commons Attribution (CC BY) license (http://creativecommons.org/licenses/by/4.0/). 